\title{
Strengthening Health Systems; the Basis for Controlling Corona Virus Pandemics
}

\author{
Fateme Sedghi ${ }^{1,}{ }^{,}$, Mahdi Gholian Aval (iD ${ }^{2}$ and Mohammad Vahedian Sharoodi (iD ${ }^{2}$ \\ ${ }^{1}$ Student Research Committee, Social Determinants of Health Research Center, Mashhad University of Medical Sciences, Mashhad, Iran \\ ${ }^{2}$ Department of Health Education and Health Promotion School of Health, Social Determinants of Health Research Center, Mashhad University of Medical Sciences, \\ Mashhad, Iran \\ "Corresponding author: Student Research Committee, Social Determinants of Health Research Center, Mashhad University of Medical Sciences, Mashhad, Iran. Email: \\ sedghifi@mums.ac.i \\ Received 2020 June 08; Revised 2020 August 05; Accepted 2020 September 24.
}

Keywords: Health Systems, Coronavirus, Private Sector

\section{Dear editor,}

Throughout history, war and epidemics have ravaged humanity. Some epidemics have ominous connotations that no war has caused ever since. During the 20th century, several epidemics have occurred, the most well-known of which is the Spanish flu pandemic caused by the influenza A (H1N1) virus in 1918, which infected 500 million people and claimed 25 million lives. These epidemics remind us that we should be prepared at any time to confront a major pandemic (1). Nevertheless, how we cope with them has always been a fundamental issue all around the world. According to the globally available estimates, the SARS pandemic caused nearly $\$ 30$ billion economic loss in 2003, and the COVID-19 pandemic represents the largest economic shock to the global economy (2). Since accurate budget forecasts are not available for coping with future pandemics, strengthening infrastructures and implementing prevention measures, including upgrading the health care systems, can have significant benefits in the short and long term $(3,4)$. In all countries, improving health infrastructures is the most effective strategy to deal with global health crises. Health infrastructures not only include physical structures such as public health facilities, clinics, hospitals, and human resources, but also cover legal frameworks, including laws, policies, and actions of the government and the private sector regarding the public health. It also covers a wide range of preventive measures, including testing and screening, disease reporting, monitoring, quarantine, social restrictions, and vaccination, all of which should be implemented through the formulation of national laws and policies $(5,6)$.

The World Health Organization (WHO) defined the uni- versal health coverage (UHC) as a basis for ensuring the health and well-being of all people at all ages as well as the ultimate goal for all countries to achieve equitable and sustainable health outcomes. Strengthening the health system is the prerequisite of the UHC, which can be achieved by allocating necessary resources and strengthening health care facilities and institutions, to expand and increase the flexibility in providing healthcare services. A flexible health system can help the society to stay calm and avoid emotional reactions, and provides a timely response to health emergencies through timely identification and prevention of threats. Resilience to health emergencies is one of the basic and cost-effective features of structured health systems (7-9). The countries most affected by the disease, despite having access to adequate financial resources, were those that didn't strengthen their health systems effectively by investing in the UHC. So that in the face of a new pandemic, they lacked enough inpatient beds, particularly intensive care units bed, medicines, and medical equipment (e.g., ventilator). On the other hand, having access to both basic and complementary health insurance coverage also has a crucial role in the affordability of healthcare services WHO reported that countries with effective and coordinated health coverage (e.g., South Korea, Germany, Singapore, and Japan) had a better performance in the face of the COVID-19 pandemic $(8,10)$.

According to the WHO statistics, the share of the health sector from gross domestic product (GDP) is on the rise in various countries. However, governmental budgets are not enough to meet the financial needs of health systems. Many countries have resorted to various strategies to address resource shortages, including the capacities of the private sector. In other words, engaging the private sector

Copyright (C) 2020, Author(s). This is an open-access article distributed under the terms of the Creative Commons Attribution-NonCommercial 4.0 International License (http://creativecommons.org/licenses/by-nc/4.0/) which permits copy and redistribute the material just in noncommercial usages, provided the original work is properly cited. 
and shifting towards decentralization is one of the most important reforms of health systems (11). Evidence suggest that inadequate and ongoing monitoring of the private sector may negatively influence the countries' ability to deal with future epidemics (12). Nevertheless, concerning the challenges of the COVID-19 pandemic, decentralized systems may be considered as vulnerable (10). The experience of countries such as the United Kingdom, Canada, and Thailand that have used different models of publicprivate partnership (PPP) shows that engaging the private sector in providing health care services should begin from non-clinical and para-clinical services with a gradual move towards clinical services $(13,14)$.

The critical lesson from the 2014-16 West African Ebola crisis is the need for close collaboration of public and private sectors to respond to large-scale epidemics. Hence, in the era of the COVID-19 pandemic, the private sector (both for-profit and non-profit actors) role in providing health care services should be increased. In this line, increasing the participation of the private sector should be at the core of national health efforts. Currently, public facilities play the dominant role in diagnosing and treating COVID-19 patients. However, since currently there is no way to end the pandemic, close participation of both sectors is necessary. For example, private hospitals should be equipped to treat patients infected with COVID-19. This process will, of course, have to be steered by the government through a clear policy framework, developing appropriate reporting and referral systems, and having an appropriate payment system (15). The significant impact of COVID-19 on the various health, political, social, and structural dimensions of societies is an important reminder to all countries, regardless of their income, of the need to renew political commitment to improve health as a key component of sustainable development plans $(15,16)$.

According to the WHO reports, in the early stages of policy-making to prepare for the epidemic, financial barriers should be addressed by the government, and a national mobilization ought to be created, along with the organization of continuous assistance to the public and private sectors. Besides, providing more concessions for private sector participation by the government is also necessary. Regular monitoring of out-of-pocket payments and providing adequate financial support for the lower deciles, as well as using the potentials of non-governmental organizations, are effective methods to strengthen communities and to reduce harm and social pressures caused by health crises. Expanding insurance coverage, raising public awareness, ensuring adequate access to medicines, equipment, and human resources, as well as creating a targeted monitoring structure, are needed to deal with health crises, particularly in developing countries. By allocating a portion of health credits in each country, as unpredictable resources health credits, to unpredicted events and using the pooled resources in a centralized management framework, the financial aspect of addressing public health crises can be addressed.

\section{Footnotes}

Authors' Contribution: Study concept and design: FS and MG. Analysis and interpretation of data: FS, MG, and MV. Drafting of the manuscript: FS. Critical revision of the manuscript for important intellectual content: FM, MG, and MV.

Conflict of Interests: The authors declare no conflicts of interest.

Funding/Support: None declared by the author.

\section{References}

1. Pan X, Ojcius DM, Gao T, Li Z, Pan C, Pan C. Lessons learned from the 2019-nCoV epidemic on prevention of future infectious diseases. Microbes Infect. 2020;22(2):86-91. doi: 10.1016/j.micinf.2020.02.004. [PubMed: 32088333]. [PubMed Central: PMC7102576].

2. Marty AM, Jones MK. The novel Coronavirus (SARS-CoV2) is a one health issue. One Health. 2020;9:100123. doi: 10.1016/j.onehlt.2020.100123. [PubMed: 32140538]. [PubMed Central: PMC7049657].

3. Dixon S, McDonald S, Roberts J. The impact of HIV and AIDS on Africa's economic development. BMJ. 2002;324(7331):232-4. doi: 10.1136/bmj.324.7331.232. [PubMed: 11809650]. [PubMed Central: PMC1122139].

4. Keogh-Brown MR, Smith RD. The economic impact of SARS: how does the reality match the predictions? Health Policy. 2008;88(1):110-20. doi: 10.1016/j.healthpol.2008.03.003. [PubMed: 18436332]. [PubMed Central: PMC7114672].

5. Lai CC, Shih TP, Ko WC, Tang HJ, Hsueh PR. Severe acute respiratory syndrome coronavirus 2 (SARS-CoV-2) and coronavirus disease-2019 (COVID-19): The epidemic and the challenges. Int J Antimicrob Agents. 2020;55(3):105924. doi: 10.1016/j.ijantimicag.2020.105924. [PubMed: 32081636]. [PubMed Central: PMC7127800].

6. Patel A, Jernigan DB, nCo VT. Initial Public Health Response and Interim Clinical Guidance for the 2019 Novel Coronavirus Outbreak - United States, December 31, 2019-February 4, 2020. MMWR Morb Mortal Wkly Rep. 2020;69(5):140-6. doi: 10.15585/mmwr.mm6905e1. [PubMed: 32027631]. [PubMed Central: PMC7004396].

7. Bhardwaj R. Mitigating the Adverse Consequences of Pandemics: A Short Note with a Special Reference to COVID-19. SSRN Electron J. 2020. doi: $10.2139 /$ ssrn.3565460.

8. Baldwin R, Tomiura E. Thinking ahead about the trade impact of COVID-19. Economics in the Time of COVID-19. 2020;59.

9. Raoofi A, Takian A, Akbari Sari A, Olyaeemanesh A, Haghighi H, Aarabi M. COVID-19 Pandemic and Comparative Health Policy Learning in Iran. Arch Iran Med. 2020;23(4):220-34. doi: 10.34172/aim.2020.02. [PubMed: 32271594].

10. De Ceukelaire W, Bodini C. We Need Strong Public Health Care to Contain the Global Corona Pandemic. Int J Health Serv. 2020;50(3):276-7. doi: 10.1177/0020731420916725. [PubMed: 32188308]. [PubMed Central: PMC7140782]. 
11. Jamali D. Success and failure mechanisms of public private partnerships (PPPs) in developing countries. Int J Public Sector Manag. 2004;17(5):414-30. doi: 10.1108/09513550410546598.

12. Sampath P, Wilson D. A case study and state of science review: private versus public healthcare financing. Glob J Health Sci. 2011;4(1):11826. doi: 10.5539/gjhs.v4n1p118. [PubMed: 22980105]. [PubMed Central: PMC4777022].

13. Nikolic IA, Maikisch H. Public-private partnerships and collaboration in the health sector: an overview with case studies from recent European experience. 2006.
14. Evans TG, Chowdhury AMR, Evans DB, Fidler A, Lindelow M, Mills A, et al. Thailand's universal coverage scheme: achievements and challenges. An Independent Assessment of the First. 2012;10:2001-10.

15. Shrivastava SRL, Shrivastava PS. Corona virus disease 2019 pandemic: Necessity for active engagement of the private sector. Dent Med Res. 2020;8(1). doi: 10.4103/dmr.dmr_6_20.

16. Arimoro A. The Corona Virus (COVID-19) Pandemic and the Challenge of Healthcare Infrastructure in Nigeria: What Role for Public-Private Partnerships. PrePrint. 2020. doi: 10.20944/preprints202006.0340.v1. 